\title{
ARACHIDONIC ACID PRODUCTION BY MORTIERELLA ALPINA USING RAW CROP MATERIALS
}

\author{
Ganggang Cao, Zhengbing Guan, Feixiang Liu, Xiangru Liao, Yujie Cai ${ }^{凶}$ \\ The Key Laboratory of Industrial Biotechnology, Ministry of Education, School of Biotechnology, Jiangnan University \\ 1800 Lihu Road, Wuxi, Jiangsu, China
}

\begin{abstract}
Background. Arachidonic acid (ARA) is one of the three essential fatty acids, and it is important for human body to keep healthy and is widely used. At present, expensive materials such as glucose and yeast extract are generally reported to be optimal for ARA production. A new cost-effective fermentation process including cheaper material for ARA production is of great significance.

Material and methods. Feasibility of using corn meal and powdered soybean for fungal growth and lipid accumulation was evaluated by means of single factor test. N-hexadecane concentration was optimized, and the effect of temperature on biomass and ARA content was examined.

Results. Mortierella alpina made better use of the aforementioned material as carbon and nitrogen sources for both hyphae growth and ARA production compared with glucose and yeast extract. Maximal levels of $10.9 \mathrm{~g} / \mathrm{L}$ ARA and $26.1 \mathrm{~g} / \mathrm{L}$ total lipids were obtained when $66 \mathrm{~g} / \mathrm{L}$ corn meal, $54 \mathrm{~g} / \mathrm{L}$ soybean meal and $6 \%(\mathrm{v} / \mathrm{v}) \mathrm{n}$-hexadecane were supplemented. A temperature-shift strategy involved three steps, namely, $30^{\circ} \mathrm{C}$ (3 days) $-25^{\circ} \mathrm{C}$ (4 days) $-20^{\circ} \mathrm{C}$ (4 days), which further improved ARA production by $24.7 \%$.

Conclusion. Several factors such as carbon and nitrogen sources, temperature and dissolved oxygen had great influence on biomass and microbial oil production. Mortierella alpina preferred corn and soybean meal compared with glucose and yeast extract, which would surely alleviate the high cost of ARA production. Based on this study, the new process is both low cost and practicable.
\end{abstract}

Key words: raw crop materials, n-hexadecane, temperature shift, arachidonic acid, Mortierella alpina

\section{INTRODUCTION}

Arachidonic acid (5,8,11,14-cis-eicosatetraenoic acid, ARA) is an important member of the $\omega-6$ series of polyunsaturated fatty acids (PUFAs) that can be used in the treatment of heart and circulatory disorders, cancer and play some role in inflammatory reactions (Demaison and Moreau, 2002; Gil, 2002; Ratledge, 2004; Willett et al., 1993). Furthermore, arachidonic acid is also the direct precursor of some physiologically important hormones, such as prostaglandins and leukotrienes in mammals (Marx, 1982), and plays an important role in maintaining physical homeostasis (Carlson et al.,
1999) and intracellular signalling at various stages of growth and development (Kragballe and Voorhees, 1983). In recent years, an increasing public awareness of healthy foods has brought ARA, an essential fatty acid, to the attention of consumers. Due to the many health-promoting benefits, ARA has been widely studied in the food, medical, cosmetics, pharmacology, agricultural and many other fields.

In recent years, large-scale bioconversion techniques have been developed to transform starchy materials, especially corn starch, to microbial products 
(Cheng et al., 1991; Mc Aloon et al., 2000; Zhu et al., 2003). Given the capacity for secreting extracellular amylolytic enzymes in another species, namely Mortierella alliacea (Tanaka et al., 2002), Mortierella alpina, an saprophagous organism belonging to the $\mathrm{Zy}-$ gomycetes phylum, most likely shares this ability and can directly ferment crop starch to microbial lipids. Current agricultural technology and increasing crop yields provide sufficient feedstock for the fermentation industry, including ARA production. At present, expensive materials such as glucose and yeast extract are generally reported to be optimal for M. alpina growth and lipid accumulation (Bajpai et al., 1991; Chen et al., 1997; Shinmen et al., 1989). These materials are used for commercial scale production of ARA. -Therefore, to explore a new and low-cost source is crucial for surmounting the supply quandary and realising a wider application of ARA.

The aim of this study was to investigate the feasibility of using corn and soybean dry milling for ARA production and to develop a new process for low-cost and effective production of ARA.

\section{MATERIAL AND METHODS}

\section{Microorganism}

Mortierella alpina ATCC 32222 was used in the following study. The organism was maintained on a potato dextrose agar slant and subcultured every three months.

\section{Media and culture conditions}

Corn and soybean meal was purchased from a local market with maximum particle sizes of 0.20 and $0.05 \mathrm{~mm}$, respectively.

The basal medium comprised $3 \mathrm{~g} / \mathrm{L} \mathrm{KH}_{2} \mathrm{PO}_{4}, 1 \mathrm{~g} / \mathrm{L}$ $\mathrm{Na}_{2} \mathrm{SO}_{4}, 0.5 \mathrm{~g} / \mathrm{L} \mathrm{MgSO}_{4} \cdot 7 \mathrm{H}_{2} \mathrm{O}$, and $0.5 \mathrm{~g} / \mathrm{L} \mathrm{CaCl}_{2}$, with $\mathrm{pH}$ uncontrolled. The inoculum was prepared in 250 $\mathrm{ml}$ Erlenmeyer flasks containing $50 \mathrm{~mL}$ of basal media supplemented with $40 \mathrm{~g} / \mathrm{L}$ corn meal. Seed culture was grown at $30^{\circ} \mathrm{C}$ for $36 \mathrm{~h}$ with shaking at $200 \mathrm{rpm}$. The inoculum $(10 \%, \mathrm{v} / \mathrm{v})$ was inoculated into flasks containing $50 \mathrm{~mL}$ of production media. The production culture was incubated on an orbital shaker for 7 days at $30^{\circ} \mathrm{C}$ unless otherwise stated.

$\alpha$-amylase (EC 3.2.1.1) and glucoamylase (EC 3.2.1.3; Ruiyang Biotech Co., Ltd., China) were employed to hydrolyze starch in corn meal and soybean meal.

\section{Analytical procedures}

Cell dry weight. Dry cell weight (DCW) was determined gravimetrically by filtration of the filamentous pellet suspension using a double-layer gauze and washing with a large amount of distilled water to guarantee complete removal of residues to reduce the amount of starch adhered to the surface of the filamentous pellet. The pellet was dried at $70^{\circ} \mathrm{C}$ to a constant weight.

Lipid extraction. Total fatty acids (TFA) were extracted with chloroform/methanol $(2: 1, \mathrm{v} / \mathrm{v})$, following a modified method of Bligh and Dyer (1959). During which the dry mycelium was ground into a fine powder and subjected to cell lysis by diluted hydrochloric acid $(20 \%, \mathrm{w} / \mathrm{v})$ at $80^{\circ} \mathrm{C}$ for an hour. The extraction process was repeated three times. The chloroform layer containing dissolved lipids was removed and vacuum-dried.

Analysis of fatty acid composition. Saponification and esterification of TFA were performed to produce fatty acid methyl esters (FAME). First, $50 \mu \mathrm{L}$ of TFAs were transferred into a tube and incubated at $70^{\circ} \mathrm{C}$ for $30 \mathrm{~min}$, followed by the addition of $2 \mathrm{~mL} \mathrm{KOH}(0.5$ M) in methanol. Next, fatty acid salts were methylated by $2 \mathrm{~mL}$ boron trifluoride in methanol according to the protocol described by Metcalfe and Schmitz (1961). FAME were identified using gas chromatographymass spectrometry (1200LGC/MS-MS, Varian, USA) equipped with a flame ionization detector and a capillary column $(30 \mathrm{~m} \times 0.25 \mathrm{~mm} \times 0.25 \mu \mathrm{m})$, and quantified by heptadecanoic acid as an internal standard.

\section{Raw material and spent medium characterisations.}

Total carbohydrate was quantified by the phenol-sulfuric acid method (Dubois et al., 1956). Reducing sugars were measured by the dinitrosalicylic acid method (Ghose, 1987). Starch content was estimated by subtracting the reducing sugars from the total reduced sugars in the hydrolysates of raw materials and residuals. Soxhlet extraction was applied to detect the lipids. Crude protein content was calculated by multiplying total nitrogen, obtained using the Kjeldahl method, by a factor of 6.25. The contents of the other components 
were determined according to the national standard of China (GB/T 1995).

The oxygen mass transfer coefficient, $k_{L} a$, was measured according to the dynamic method (Tribe et al., 1995). The viscosity of the broth was determined by a rotational viscometer (NDJ-1, Nirun, China).

All data presented in this article were derived from three independent trials to ensure validity.

\section{RESULTS AND DISCUSSION}

\section{Characterisation of dry corn and soybean meal}

The characterisation of corn and soybean meal indicated the presence of various organic compounds in the raw materials (Table 1).

The carbohydrate content of corn was greater than $70 \%$, while it was less than $40 \%$ in soybean. Raw corn and soybean meal contained more oil and proteins than hulled and de-embryonated ones, which were expected to favour M. alpina growth and lipid accumulation, as large amounts of saturated and unsaturated fatty acids can be directly assimilated by fungi and used as precursors for microbial lipid production, which would surely accelerate lipid synthesis (Aki et al., 2001; Shinmen et al., 1989). Starch-rich corn and protein-rich soybean serve as sources of carbon and nitrogen, respectively. However, in contrast to corn-ethanol production, which involves the removal of cornhusks and plantule before hydrolysis by $\alpha$-amylase and glucoamylase, these structures are

Table 1. Approximate analysis of raw corn and soybean meal

\begin{tabular}{lcc}
\hline \multicolumn{1}{c}{ Constituents } & Corn meal, \% & Soybean meal, \% \\
\hline Moisture & $8.4 \pm 0.7$ & $7.6 \pm 0.5$ \\
Protein & $7.9 \pm 0.6$ & $28 \pm 1.7$ \\
Total fat & $6.0 \pm 0.8$ & $20.5 \pm 2.3$ \\
Carbohydrates & $73.3 \pm 4.2$ & $37 \pm 3.7$ \\
Cellulose & $2.1 \pm 0.4$ & $1.7 \pm 0.2$ \\
Ash & $2.3 \pm 0.3$ & $5.2 \pm 0.3$ \\
\hline
\end{tabular}

*Total carbohydrates include primarily starch and reducing sugar among which the former dominates. retained. The high nitrogen content benefits fungal growth, so that higher lipid production can be achieved. Furthermore, some microelements and growth-promoting factors such as vitamins in the unprocessed meal may play critical but unknown roles for growth and lipid accumulation.

\section{Effect of different carbon sources on cell growth, total lipid yield and ARA production}

Carbon source is one of the most important factors that influences microbial growth and product formation. Carbon constitutes the carbon chain of the cell and metabolites. Intracellular lipids are mainly present in the form of triglycerides, and the main element is carbon. Therefore, to obtain high-yield of biomass and lipids, the best carbon source in terms of both growth and lipid accumulation should be found.

Figure 1 shows biomass, total lipids and ARA yield using different carbon sources. Starch was most favourable for cell growth. Biomass derived from medium containing soluble starch or corn meal was much higher than other carbon sources. Relatively higher total lipid and ARA yield were achieved when these two carbon sources were used, in respect that lipids were intracellular products. Previous studies generally

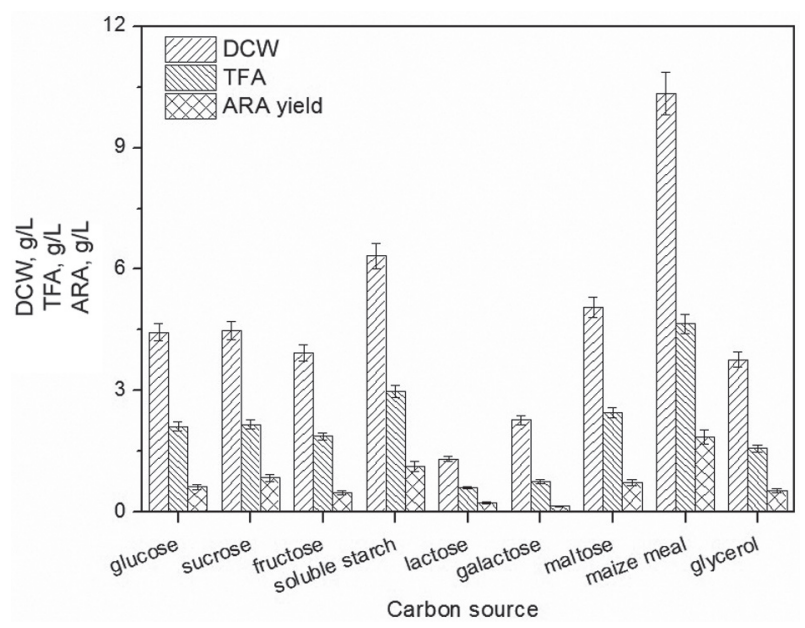

Fig. 1. Effect of different carbon sources on biomass, total fatty acid yield and ARA production. Yeast extract was used as the nitrogen source. Cultures were maintained by shaking at $30^{\circ} \mathrm{C}$ and $200 \mathrm{rpm}$ for 7 days. Error bars represent standard deviations 
reported that glucose was the best carbon source for production of ARA by M. alpina (Higashiyama et al., 2002; Shinmen et al., 1989). The difference may be due to the specific strain used. In addition, the direct use of corn meal in submerged fermentation for ARA production had not been specifically reported. The use of corn meal as a carbon source can not only greatly reduce the cost of materials but also result in higher yield. The highest biomass and ARA production reached $10.34 \mathrm{~g} / \mathrm{L}$ and $1.86 \mathrm{~g} / \mathrm{L}$, respectively, nearly three times as much as glucose.
Growth morphology in cultures containing different carbon sources is shown in Figure 2. Mortierella alpina generally appeared as pellets in all cultures. Higashiyama et al. (1998) reported that pellets with a particle size of approximately 1-2 $\mathrm{mm}$ were optimal for ARA production. Large pellets often resulted in low biomass, while very small pellets caused high viscosity. The morphology of M. alpina grown on corn meal (Fig. $2 \mathrm{H}$ ) was feather-like and was previously shown to be suitable for ARA production (Park et al., 1999).

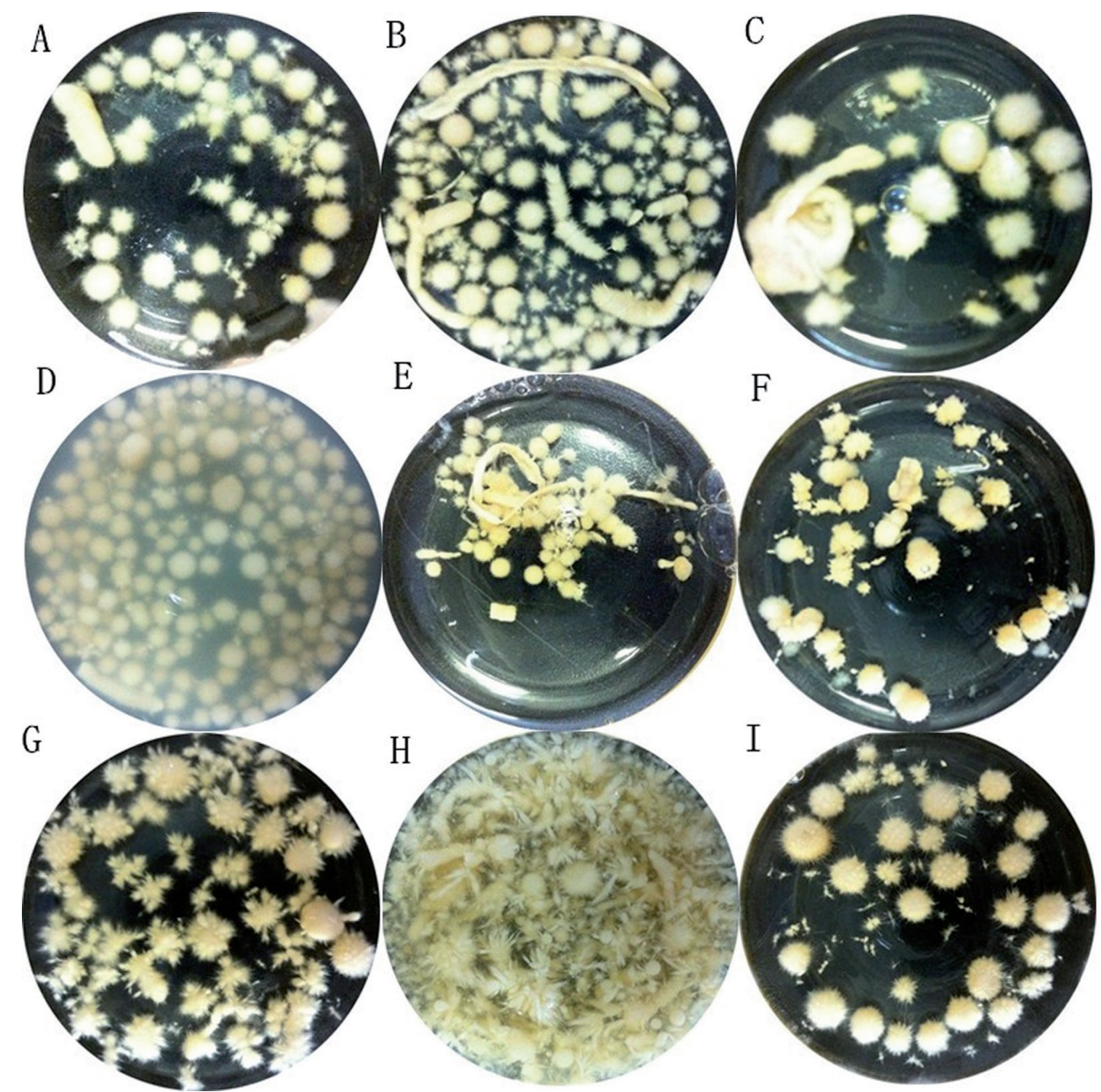

Fig. 2. Growth morphology of M. alpina in medium containing different carbon sources. Pictures were taken at the end of fermentation in flasks containing carbon sources in the following order: glucose, sucrose, fructose, soluble starch, lactose, galactose, maltose, maize meal, glycerol 


\section{Effect of different nitrogen sources} on cell growth, total lipid yield and ARA production Nitrogen is another key factor determining ARA production. Nitrogen sources provide nitrogen for fermentation systems. Although nitrogen is not directly involved in ARA elements, it is essential for the production of ARA and formation of cellular components by the catalytic system, thereby indirectly affecting ARA production. An excellent nitrogen source should be one that is easily assimilated and promotes cell growth. Figure 3 shows biomass, total lipids and ARA yield using different nitrogen sources. The soybeanderived biomass reached $14.4 \mathrm{~g} / \mathrm{L}$, nearly doubled that of yeast extract and higher than that of corn meal. A possible explanation was that soybean contained more protein and oil, which favored cell growth more than corn (Table 1). In addition, the profile of M. alpi$n a$ grown on different nitrogen sources (Fig. 3) indicated that the strain cannot easily assimilate inorganic nitrogen, as indicated by the observed poor growth.

It has been reported that inorganic and organic nitrogen play different roles during cellular biomass and lipid accumulation and that inorganic nitrogen is more beneficial in biomass accumulation (Evans and Ratledge, 1984; Somashekar et al., 2003). Obviously,

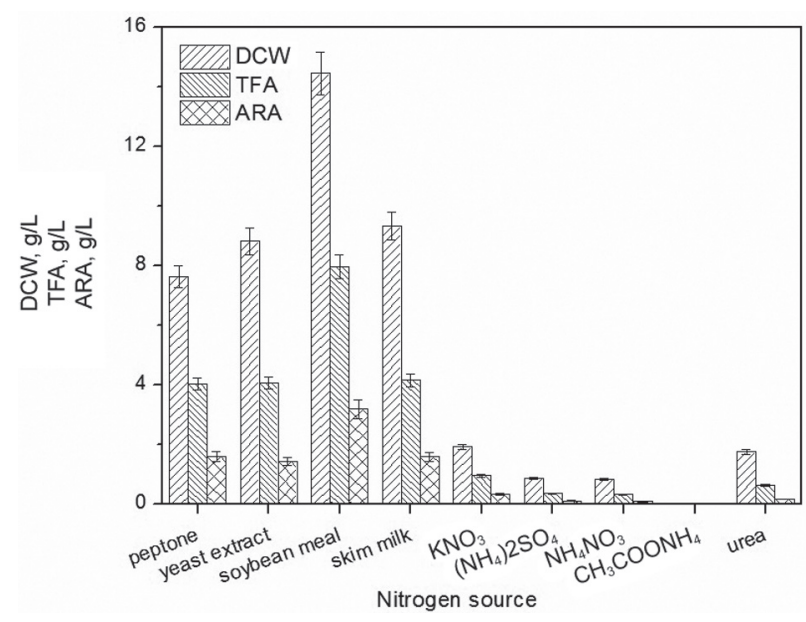

Fig. 3. Effect of different nitrogen sources on biomass, total fatty acid yield and ARA production. Glucose was used as the carbon source. Cultures were maintained by shaking at $30^{\circ} \mathrm{C}$ and $200 \mathrm{rpm}$ for 7 days. Error bars represent standard deviations
M. alpina does not share the same mechanism. Taken together, starch-contained raw materials are preferred by $M$. alpina for fungal growth, lipid accumulation and ARA production compared with other carbon and nitrogen sources studied in this work.

Growth morphology in cultures containing different nitrogen sources was shown in Figure 4. Mortierella alpina appeared as pellets in all nitrogen-containing cultures. The morphology of M. alpina grown on corn meal and skim milk (Fig. 4 C, D) was optimal for ARA production.

\section{Effect of initial carbon to nitrogen ratio and substrate concentration on cell dry weight, lipid yield and ARA production}

To investigate the effect of $\mathrm{C} / \mathrm{N}$ ratio and ' $\mathrm{C}+\mathrm{N}$ ' concentration on the profiles of $M$. alpina, cultures were prepared where either the $\mathrm{C} / \mathrm{N}$ ratio was constant but ' $\mathrm{C}+\mathrm{N}$ ' concentration varied (ranging from 40 to $120 \mathrm{~g} / \mathrm{L}$ ) or the ' $\mathrm{C}+\mathrm{N}$ ' concentration was constant but the $\mathrm{C} / \mathrm{N}$ ratio varied (ranging from 13 to 28 ; Table 2).

As shown in Table 2, lipid content increased with rising $\mathrm{C} / \mathrm{N}$ ratio. TFA/DCW in cultures with a $\mathrm{C} / \mathrm{N}$ ratio of 28 was approximately four percent higher than cultures with a ratio of 13 . However, biomass concentration was at a maximum when the $\mathrm{C} / \mathrm{N}$ ratio was 13 , an opposite relationship vs. lipid content in dry cell weight. Therefore, it can be concluded that low $\mathrm{C} / \mathrm{N}$ ratio was good for cell growth, while high $\mathrm{C} / \mathrm{N}$ ratio favored lipid accumulation, which was most likely due to the 'growth-promoting effect' of nitrogen. The effect of $\mathrm{C} / \mathrm{N}$ ratio had also been observed by many other researchers using different strains and media (Koike et al., 2001; Šajbidor et al., 1990). Some oleaginous microalgae and yeast shared the same pattern at different $\mathrm{C} / \mathrm{N}$ ratios. The highest lipid concentration of $21.9 \mathrm{~g} / \mathrm{L}$ was obtained at a $\mathrm{C} / \mathrm{N}$ ratio of 19 which was moderate for both fungus growth and lipid accumulation.

There was little variability in ARA/TFA with different $\mathrm{C} / \mathrm{N}$ ratios, with values generally approximately $30 \%$. As shown in Table 2, the ARA content in total fatty acids decreased with rising substrate concentration and cell dry weight. This may be due to a low dissolved oxygen concentration caused by the high viscosity of the starchy media after autoclaving because of starch swelling and the high density of the cell pellets in the broth. 

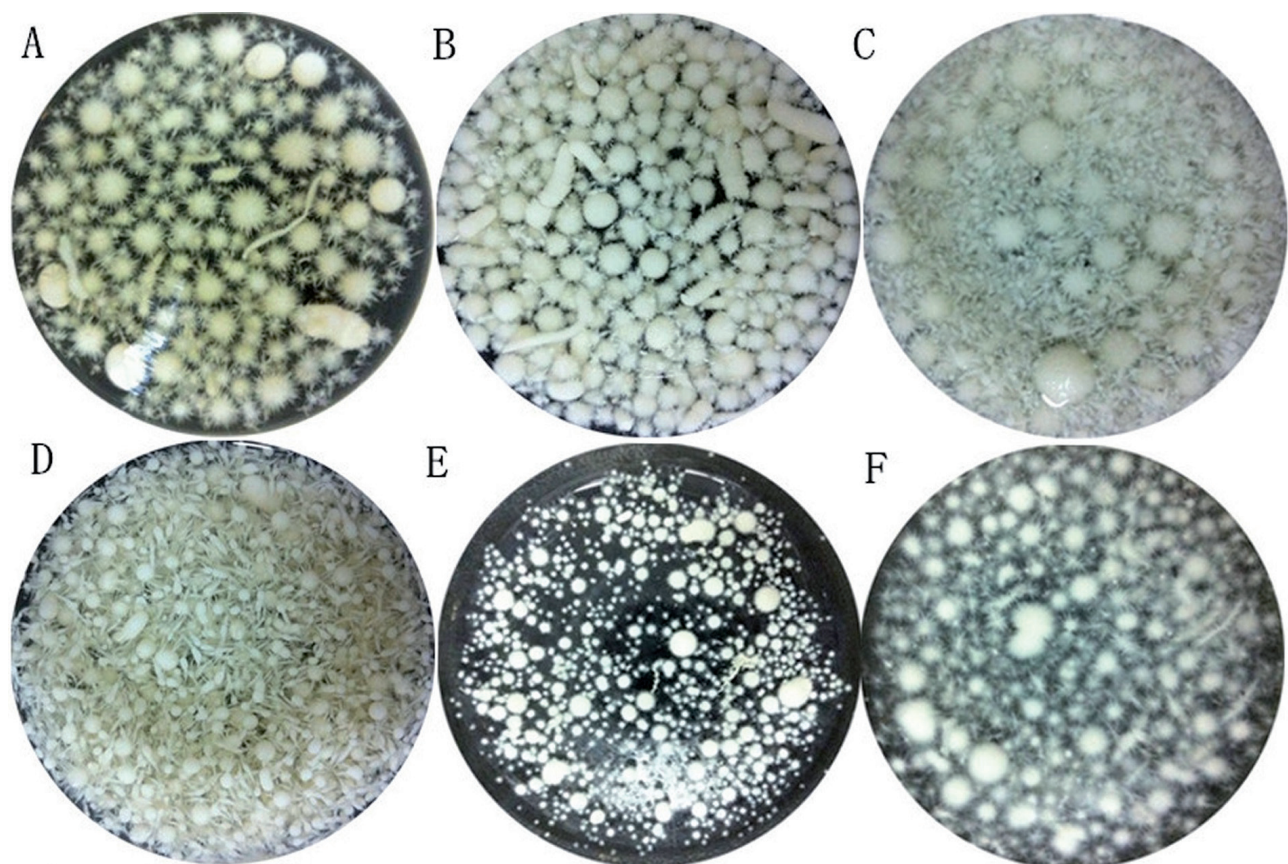

E
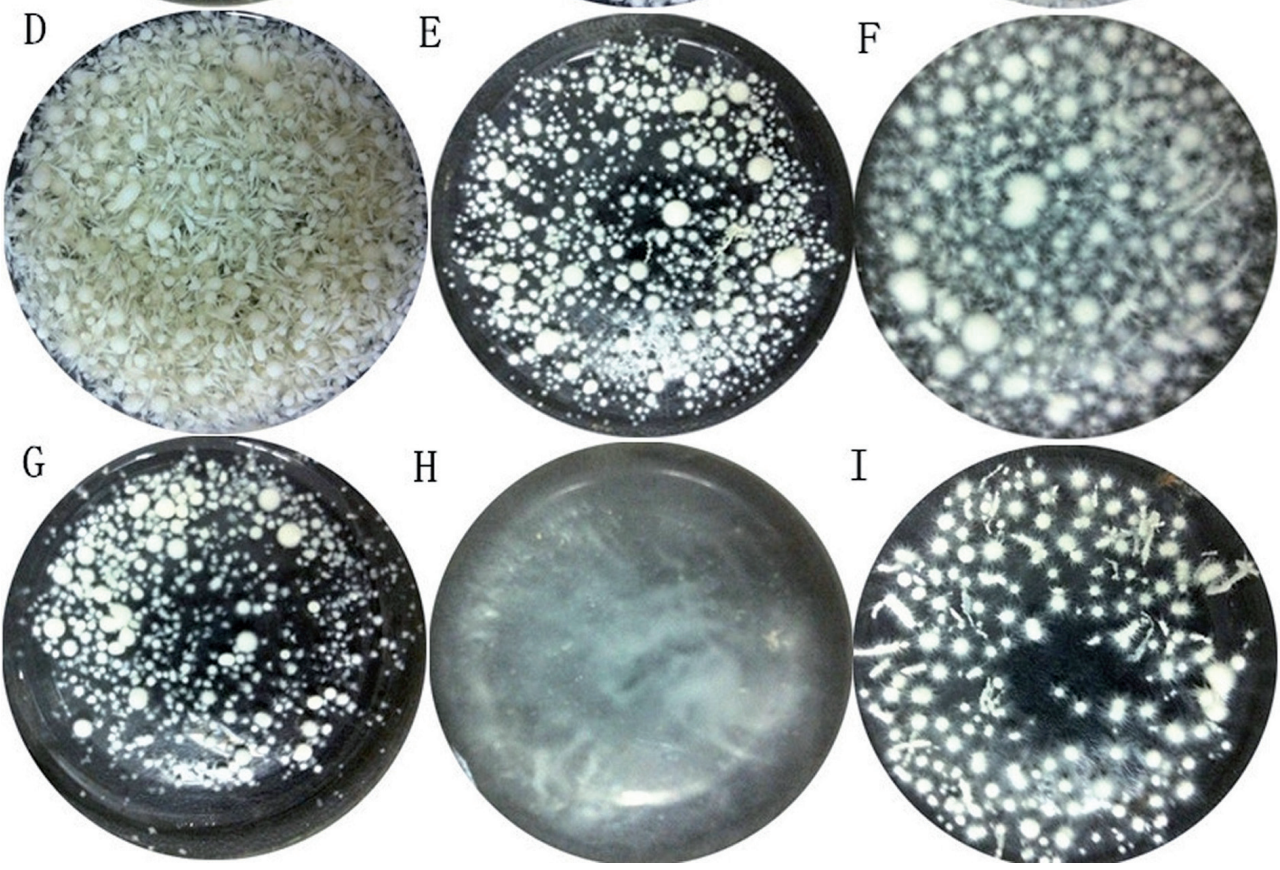

Fig. 4. Growth morphology of M. alpina in medium containing different nitrogen sources. Pictures were taken at the end of fermentation in flasks containing carbon sources in the following order: peptone, yeast extract, soybean meal, skim milk, potassium nitrate, ammonium sulfate, ammonium nitrate, ammonium acetate, urea

Biomass production increased dramatically with increasing substrate concentration at a fixed $\mathrm{C} / \mathrm{N}$ ratio. For intracellular lipid accumulation, high biomass was preferred. Based on all processed data and the above analysis, we chose a $\mathrm{C} / \mathrm{N}$ ratio of 19 and substrate concentration of $120 \mathrm{~g} / \mathrm{L}$, equivalent to $66 \mathrm{~g} / \mathrm{L}$ corn meal and $54 \mathrm{~g} / \mathrm{L}$ soybean meal as the best $\mathrm{C} / \mathrm{N}$ ratio and substrate concentration. The highest biomass, lipid and ARA levels of 44.7, 21.9 and $7.3 \mathrm{~g} / \mathrm{L}$, respectively, were achieved under these conditions.
The mycelial morphology of $M$. alpina growing in the abovementioned media was shown in Figure 5 B. Large numbers of small smooth pellets, approximately $2 \mathrm{~mm}$ on average, were evenly distributed in the culture. Smooth pellets were known to lower the viscosity of broth compared with filamentous morphology. Furthermore, smooth pellets allowed continuous cultivation of filamentous fungi, which is often problematic because of the difficulty in the continuous removal of broth through the overflow pipe of fermentor due to high adhesiveness (Eroshin et al., 2000). 
Cao, G., Guan, Z., Liu, F., Liao, X., Cai, Y. (2015). Arachidonic acid production by Mortierella alpina using raw crop materials. Acta Sci. Pol. Technol. Aliment., 14(2), 133-143. DOI: 10.17306/J.AFS.2015.2.15

Table 2. Effect of $\mathrm{C} / \mathrm{N}$ ratio and substrate concentration on biomass, total fatty acid yield, and ARA production in $M$. alpina

\begin{tabular}{|c|c|c|c|c|c|}
\hline \multirow{2}{*}{$\begin{array}{l}\mathrm{C} / \mathrm{N} \\
\text { ratio }\end{array}$} & $\mathrm{SC}$ & DCW & TFA & ARA & \multirow{2}{*}{$\begin{array}{c}\begin{array}{c}\text { ARA/ } \\
\text { TFA }\end{array} \\
\%\end{array}$} \\
\hline & \multicolumn{4}{|c|}{$\mathrm{g} / \mathrm{L}$} & \\
\hline \multirow[t]{3}{*}{13} & 40 & $14.6 \pm 0.2$ & $6.7 \pm 0.3$ & $2.0 \pm 0.2$ & 29.8 \\
\hline & 80 & $30.1 \pm 0.3$ & $13.6 \pm 0.5$ & $3.9 \pm 0.4$ & 28.7 \\
\hline & 120 & $46.5 \pm 0.5$ & $21.0 \pm 0.9$ & $5.9 \pm 0.5$ & 28.1 \\
\hline \multirow[t]{3}{*}{16} & 40 & $14.3 \pm 0.1$ & $6.7 \pm 0.4$ & $2.2 \pm 0.1$ & 32.8 \\
\hline & 80 & $29.8 \pm 0.4$ & $13.9 \pm 0.4$ & $4.4 \pm 0.4$ & 31.6 \\
\hline & 120 & $45.5 \pm 0.8$ & $21.0 \pm 1.0$ & $6.4 \pm 0.9$ & 30.5 \\
\hline \multirow[t]{3}{*}{19} & 40 & $13.5 \pm 0.4$ & $6.7 \pm 0.5$ & $2.3 \pm 0.2$ & 34.3 \\
\hline & 80 & $29.1 \pm 0.7$ & $14.4 \pm 0.7$ & $4.9 \pm 0.6$ & 34.0 \\
\hline & 120 & $44.7 \pm 1.1$ & $21.9 \pm 1.1$ & $7.3 \pm 1.1$ & 33.3 \\
\hline \multirow[t]{3}{*}{22} & 40 & $13.1 \pm 0.3$ & $6.5 \pm 0.3$ & $2.1 \pm 0.3$ & 32.3 \\
\hline & 80 & $26.8 \pm 0.5$ & $13.2 \pm 0.6$ & $4.2 \pm 0.7$ & 31.8 \\
\hline & 120 & ND & ND & ND & ND \\
\hline \multirow[t]{3}{*}{25} & 40 & $12.8 \pm 0.2$ & $6.4 \pm 0.9$ & $2.0 \pm 0.3$ & 31.2 \\
\hline & 80 & $24.2 \pm 0.5$ & $12.1 \pm 1.1$ & $3.5 \pm 0.6$ & 28.9 \\
\hline & 120 & ND & ND & ND & ND \\
\hline \multirow[t]{3}{*}{28} & 40 & $11.9 \pm 0.3$ & $6.0 \pm 0.8$ & $1.7 \pm 0.2$ & 28.3 \\
\hline & 80 & $22.6 \pm 0.7$ & $11.4 \pm 0.4$ & $3.0 \pm 0.5$ & 26.3 \\
\hline & 120 & ND & ND & ND & ND \\
\hline
\end{tabular}

Cultures were maintained shaking at $30^{\circ} \mathrm{C}$ and $200 \mathrm{rpm}$ for 7 days with corn and soybean meal used as the main nutrients. $\mathrm{SC}$ - substrate concentration.

ND - medium with high proportion and concentration of corn meal appears a semi-solid state after autoclaving and can't be homogenized by the shaker.

All data are deprived from three replicates and expressed as average \pm standard deviation.

\section{Effect of $\mathrm{n}$-hexadecane concentration on the profiles of M. alpina}

ARA fermentation by M. alpina is aerobic. ARA is formed through elongation and desaturation from a carbon source in the mycelia following the $n-6$ pathway. The desaturation step involves an aerobic

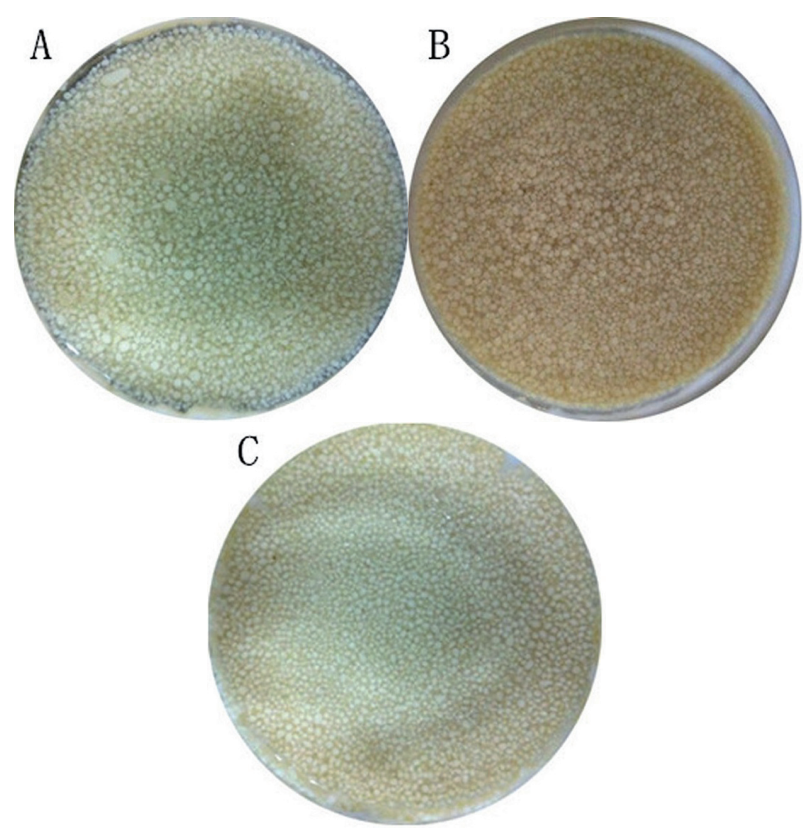

Fig. 5. Growth morphology of M. alpina in medium containing: A - $20 \mathrm{~g} / \mathrm{L}$ corn meal, $18 \mathrm{~g} / \mathrm{L}$ soybean meal; B $66 \mathrm{~g} / \mathrm{L}$ corn meal and $54 \mathrm{~g} / \mathrm{L}$ soybean meal; $\mathrm{C}-66 \mathrm{~g} / \mathrm{L}$ corn meal, $54 \mathrm{~g} / \mathrm{L}$ soybean meal and $6 \%(\mathrm{v} / \mathrm{v}) \mathrm{n}$-hexadecane

reaction by oxygenation (Ratledge, 1992). Consequently, dissolved oxygen (DO) seems to be an important factor determining ARA yield (Higashiyama et al., 1999), especially in highly viscous medium. The optimal media accomplished in this study contained nearly $70 \mathrm{~g}$ of starch per liter. Starch gelatinization caused by high temperatures substantially increased the viscosity of the media, which ultimately resulted in limited biomass and lipid accumulation. In light of this challenge, many attempts had been made to improve the rheology of broth to enhance DO concentration (Emelyanova, 1997; Hansson et al., 1989; Preez et al., 1997). N-hexadecane was supplemented in media and used as an oxygen vector in the present work. N-hexadecane can act as a surface active agent to lower the surface tension of water and increase the gas-specific interfacial area (Zhang et al., 2008).

As shown in Figure 6, DCW and ARA/TFA both increased with rising concentrations of n-hexadecane 


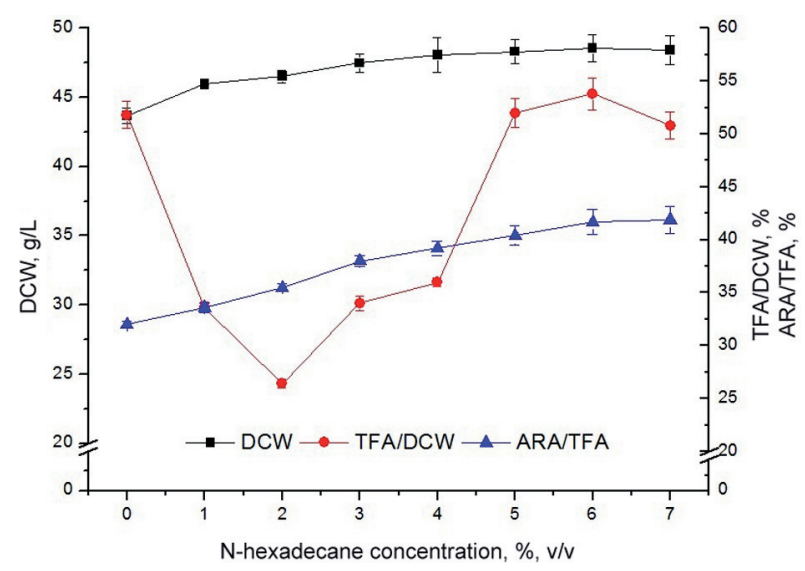

Fig. 6. Effects of $\mathrm{n}$-hexadecane concentration on M. alpina cell growth, total fatty acid content, and ARA content in total fatty acids. Cultures were maintained at $30^{\circ} \mathrm{C}$ with shaking at $200 \mathrm{rpm}$ for 7 days in medium containing $66 \mathrm{~g} / \mathrm{L}$ corn meal and $54 \mathrm{~g} / \mathrm{L}$ soybean meal

compared with the control. TFA and ARA levels reached plateaus of 28.1 and $11.7 \mathrm{~g} / \mathrm{L}$, respectively, with $6 \%(\mathrm{v} / \mathrm{v}) \mathrm{n}$-hexadecane added. The $k_{L} a$ value increased from $20 \mathrm{~h}^{-1}$ to $50 \mathrm{~h}^{-1}, 150 \%$ increasement compared to the control. On the contrary, the average viscosity of the broth decreased from $6.5 \mathrm{~Pa} \cdot \mathrm{s}$ to $3.1 \mathrm{~Pa} \cdot \mathrm{s}$ (measured at $30^{\circ} \mathrm{C}$ ). Therefore, the addition of $6 \% \mathrm{n}$-hexadecane (v/v) significantly improved rheology and increased the DO value. The morphology of M. alpina in 6\% (v/v) n-hexadecane-containing medium was shown in Figure 5 C. Apparently, the supplementation of $\mathrm{n}$-hexadecane reduced broth viscosity and promoted its homogeneity. However, TFA/DCW showed an inverse relationship when added at low levels, while its levels were elevated higher than the control when the additive volume exceeded $6 \%(\mathrm{v} / \mathrm{v})$. It seemed that small amounts of n-hexadecane inhibited intracellular lipid synthesis while high levels of n-hexadecane promoted it. One possible reason was that the physical chemistry of broth was altered as n-hexadecane concentration changed. Moreover, it was reported that some microorganisms can directly grow on alkane as a single carbon source and use it as a precursor for fatty acid production (Desai and Banat, 1997). High concentrations of n-hexadecane appeared to be assimilated by M. alpi$n a$ and improve lipid accumulation.

\section{Effect of culture temperature and temperature shift on cell growth, lipid yield and ARA production}

Temperature was found to be an important factor influencing fungal growth and fatty acid composition. Lipids, including ARA, are intracellular metabolites, and their yields are determined by biomass. Therefore, it is very important to find an optimal temperature for cell growth and product formation. A previous study reported that biomass and ARA concentration decreased when culture temperature was switched from $25^{\circ} \mathrm{C}$ to $28^{\circ} \mathrm{C}$ (Peng et al., 2010). It was also observed that low culture temperature favored highly unsaturated fatty acid production, as it promoted desaturation reactions, while cell growth was concurrently retarded (Liang et al., 2012). Peng et al. (2010) developed a temperature shift strategy for efficient ARA fermentation by $M$. alpina, in which the culture temperature was maintained at $25^{\circ} \mathrm{C}$ for the first $108 \mathrm{~h}$, then switched to $20^{\circ} \mathrm{C}$. However, this strategy may not apply to the present work due to differences in strain and medium.

Growth and lipid kinetic analyses were summarized in Table 3. The evolution of cell dry weight at different temperatures indicated that higher initial growth rate was obtained at higher temperatures. In other words, the higher the temperature, the shorter the time needed for reaching the maximal biomass. Higher temperatures favoured a faster metabolism rate, resulting in more rapid cell division. As a consequence, the lag and logarithmic phases were shortened. As shown in the table, the stationary phase started on day 3 , day 5 , and day 7 for cultures incubated at 30,25 , and $20^{\circ} \mathrm{C}$, respectively. However, cell density decreased with increasing culture temperature. This phenomenon was also observed on potato slant cultures at different temperatures. When the fungus was grown at $25^{\circ} \mathrm{C}$, much more luxuriant mycelia emerged than that at $30^{\circ} \mathrm{C}$. Cell dry weight attained its maximal value of $50.4 \mathrm{~g} / \mathrm{L}$ at $20^{\circ} \mathrm{C}$ on day 7 .

Table 3 also indicated that the lipid content in cells differed slightly with varying temperatures. Nonetheless, ARA content in total lipids was closely related to the incubation temperature. ARA/TFA of $20^{\circ} \mathrm{C}-$ derived cells was $57 \%, 17 \%$ higher than that of cultures grown at $30^{\circ} \mathrm{C}$. Specifically, lower temperatures increased the degree of fatty acid unsaturation because 
Cao, G., Guan, Z., Liu, F., Liao, X., Cai, Y. (2015). Arachidonic acid production by Mortierella alpina using raw crop materials. Acta Sci. Pol. Technol. Aliment., 14(2), 133-143. DOI: 10.17306/J.AFS.2015.2.15

Table 3. Culture profiles of M. alpina grown using a constant and stepwise decreasing temperature strategy associated with prolonged incubation time

\begin{tabular}{|c|c|c|c|c|c|c|c|}
\hline \multirow{2}{*}{$\begin{array}{c}\text { Temperature } \\
{ }^{\circ} \mathrm{C}\end{array}$} & \multirow{2}{*}{$\begin{array}{c}\text { Production } \\
\mathrm{g} / \mathrm{L}\end{array}$} & \multicolumn{6}{|c|}{ Time, day } \\
\hline & & 3 & 5 & 7 & 9 & 11 & 13 \\
\hline \multirow[t]{3}{*}{20} & biomass & $34.6 \pm 0.7$ & $46.9 \pm 1.5$ & $50.2 \pm 1.3$ & $50.4 \pm 2.3$ & $50.1 \pm 0.9$ & $49.7 \pm 0.6$ \\
\hline & lipid & $13.8 \pm 0.3$ & $21.1 \pm 0.6$ & $25.7 \pm 0.8$ & $25.4 \pm 0.5$ & $24.6 \pm 0.5$ & $23.5 \pm 0.4$ \\
\hline & ARA & $5.5 \pm 0.1$ & $9.5 \pm 0.3$ & $11.8 \pm 0.5$ & $12.1 \pm 0.2$ & $12.7 \pm 0.4$ & $13.4 \pm 0.5$ \\
\hline \multirow[t]{3}{*}{25} & biomass & $40.5 \pm 1.7$ & $48.7 \pm 0.9$ & $48.8 \pm 1.3$ & $48.5 \pm 1.2$ & $47.4 \pm 0.9$ & $45.2 \pm 0.4$ \\
\hline & lipid & $16.2 \pm 0.3$ & $24.3 \pm 1.1$ & $24.6 \pm 1.6$ & $24.2 \pm 1.7$ & $23.5 \pm 0.5$ & $22.4 \pm 0.9$ \\
\hline & ARA & $4.8 \pm 0.2$ & $9.7 \pm 0.3$ & $11.1 \pm 0.5$ & $12.1 \pm 0.9$ & $11.8 \pm 0.7$ & $11.5 \pm 0.8$ \\
\hline \multirow[t]{3}{*}{30} & biomass & $44.9 \pm 1.2$ & $45.3 \pm 1.2$ & $45.1 \pm 1.4$ & $44.8 \pm 1.3$ & $43.7 \pm 0.7$ & $42.9 \pm 0.8$ \\
\hline & lipid & $18.7 \pm 0.5$ & $22.2 \pm 0.7$ & $21.8 \pm 0.3$ & $21.3 \pm 0.8$ & $20.3 \pm 0.5$ & $18.6 \pm 0.4$ \\
\hline & ARA & $5.6 \pm 0.2$ & $7.8 \pm 0.4$ & $8.7 \pm 0.9$ & $8.5 \pm 0.7$ & $8.1 \pm 0.4$ & $7.44 \pm 0.5$ \\
\hline \multirow{3}{*}{$\begin{array}{l}\text { Temperature } \\
\text { shift }^{*}\end{array}$} & biomass & $45.3 \pm 0.8$ & $48.4 \pm 1.3$ & $52.5 \pm 2.1$ & $52.7 \pm 1.8$ & $52.3 \pm 1.5$ & $51.8 \pm 1.7$ \\
\hline & lipid & $18.5 \pm 0.2$ & $21.2 \pm 0.7$ & $25.1 \pm 0.9$ & $25.2 \pm 0.4$ & $25.4 \pm 0.8$ & $24.8 \pm 0.9$ \\
\hline & ARA & $5.5 \pm 0.6$ & $8.5 \pm 0.9$ & $11.8 \pm 0.4$ & $12.5 \pm 0.9$ & $13.6 \pm 0.7$ & $13.2 \pm 0.8$ \\
\hline
\end{tabular}

All cultures were prepared in soybean and corn meal medium with $6 \%(\mathrm{v} / \mathrm{v}) \mathrm{n}$-hexadecane supplemented. *Incubation temperature was programmed as follows: maintaining at $30^{\circ} \mathrm{C}$ for the first three days, then decreased to $25^{\circ} \mathrm{C}$ until day 7 followed by another decrease to $20^{\circ} \mathrm{C}$ and kept for the last 6 days.

of the crucial nature for cells to maintain membrane fluidity. This was also confirmed by other reports (Bigogno et al., 2002; Liang et al., 2012; Shinmen et al., 1989; Singh and Ward, 1997).

Based on kinetic analysis, a temperature-shift strategy was developed as follows: the culture temperature was controlled at $30^{\circ} \mathrm{C}$ during the first 3 days to shorten the growth period, then switched to $25^{\circ} \mathrm{C}$ from day 4 to day 7 , and finally maintained at $20^{\circ} \mathrm{C}$ for the last 4 days. By applying such a temperature-shift strategy, a higher biomass, lipid and ARA yield of 52.3, 25.4, $13.6 \mathrm{~g} / \mathrm{L}$ were attained, respectively. The fermentation period was shortened by 2 days to reach maximal ARA production.

\section{CONCLUSION}

Dry corn and soybean meal were verified to be perfect for M. alpina growth and arachidonic acid production. The results also indicated that oxygen supply and temperature had great influence on biomass and microbial oil production. This thesis pays attention to the unity of theory and practice, with the intent of alleviating the high cost of ARA production. This thesis underpins the more efficient use of filamentous fungi as cell factories in ARA production. Based on this study, the process is low cost and practicable. Thorough studies on both pilot and industrial scales should be conducted in the future.

\section{REFERENCES}

Aki, T., Nagahata, Y., Ishihara, K., Tanaka, Y., ..., Morinaga, T. (2001). Production of arachidonic acid by filamentous fungus, Mortierella alliacea strain YN-15. J. Am. Oil Chem. Soc., 78, 599-604. DOI: 10.1007/ s11746-001-0311-2

Bajpai, P. K., Bajpai, P., Ward, O. P. (1991). Arachidonic acid production by fungi. Appl. Environ. Microb., 57, 1255-1258. 
Bigogno, C., Khozin-Goldberg, I., Boussiba, S., Vonshak, A., Cohen, Z., 2002. Lipid and fatty acid composition of the green oleaginous alga Parietochloris incisa, the richest plant source of arachidonic acid. Phytochemistry, 60, 497-503.

Bligh, E. G., Dyer, W. J. (1959). A rapid method of total lipid extraction and purification. Can. J. Biochem. Physiol., 37, 911-917.

Carlson, S. E., Koletzko, B., Gibson, R. A. (1999). PUFA in infant nutrition: consensus and controversies. Lipids, 34, 129-130.

Chen, H., Chang, C., Chen, C. (1997). Optimization of arachidonic acid production by Mortierella alpina Wuji-H4 isolate. J. Am. Oil Chem. Soc., 74, 569-578.

Cheng, P., Mueller, R., Jaeger, S., Bajpai, R., Iannotti, E. (1991). Lactic acid production from enzyme-thinned corn starch using Lactobacillus amylovorus. J. Ind. Microb. 7, 27-34.

Demaison, L., Moreau, D. (2002). Dietary n-3 polyunsaturated fatty acids and coronary heart disease-related mortality: a possible mechanism of action. Cell. Mol. Life Sci., 59, 463-477.

Desai, J. D., Banat, I. M. (1997). Microbial production of surfactants and their commercial potential. Microbiol. Mol. Biol., 61, 47-64.

Dubois, M., Gilles, K. A., Hamilton, J. K., Rebers, P. T., Smith, F. (1956). Colorimetric method for determination of sugars and related substances. Anal. Chem., 28, $350-356$

Emelyanova, E. V. (1997). Lipid and $\gamma$-linolenic acid production by Mucor inaquisporus. Process. Biochem., 32, 173-177. DOI: 10.1016/S0032-9592(96)00051-9

Eroshin, V., Satroutdinov, A., Dedyukhina, E., Chistyakova, T. (2000). Arachidonic acid production by Mortierella alpina with growth-coupled lipid synthesis. Process. Biochem., 35, 1171-1175.

Evans, C. T., Ratledge, C. (1984). Influence of nitrogen metabolism on lipid accumulation by Rhodosporidium toruloides CBS 14. J. Gen. Microbiol., 130, 1705-1710.

Ghose, T. (1987). Measurement of cellulase activities. Pure Appl. Chem., 59, 257-268.

Gil, A. (2002). Polyunsaturated fatty acids and inflammatory diseases. Biomed. Pharmacother., 56, 388-396.

Hansson, L., Dostálek, M., Sörenby, B. (1989). Production of $\gamma$-linolenic acid by the fungus Mucor rouxii in fedbatch and continuous culture. Appl. Microbiol. Biot., 31, 223-227.

Higashiyama, K., Fujikawa, S., Park, E. Y., Shimizu, S. (2002). Production of arachidonic acid by Mortierella fungi. Biotechn. Bioproc. Eng., 7, 252-262.
Higashiyama, K., Murakami, K., Tsujimura, H., Matsumoto, N., Fujikawa, S. (1999). Effects of dissolved oxygen on the morphology of an arachidonic acid production by Mortierella alpina 1S-4. Biotechnol. Bioeng., 63, 442-448.

Higashiyama, K., Yaguchi, T., Akimoto, K., Fujikawaa, S., Shimizu, S. (1998). Effects of mineral addition on the growth morphology of and arachidonic acid production by Mortierella alpina 1S-4. J. Am. Oil Chem. Soc., 75, $1815-1819$.

Koike, Y., Jie Cai, H., Higashiyama, K., Fujikawa, S., Park, E. Y. (2001). Effect of consumed carbon to nitrogen ratio of mycelial morphology and arachidonic acid production in cultures of Mortierella alpina. J. Biosci. Bioeng., 91, 382-389.

Kragballe, K., Voorhees, J., 1983. Arachidonic acid and leukotrienes in dermatology. J. Invest. Dermatol., 81, 293-296.

Liang, Y., Zhao, X., Strait, M., Wen, Z. (2012). Use of drymilling derived thin stillage for producing eicosapentaenoic acid (EPA) by the fungus Pythium irregulare. Biores. Technol., 111, 404-409.

Marx, J. L. (1982). The leukotrienes in allergy and inflammation. Science, 215, 1380-1383.

McAloon, A., Taylor, F., Yee, W., Ibsen, K., Wooley, R. (2000). Determining the cost of producing ethanol from corn starch and lignocellulosic feedstocks. National Renewable Energy Laboratory Report.

Metcalfe, L., Schmitz, A. (1961). The rapid preparation of fatty acid esters for gas chromatographic analysis. Anal. Chem., 33, 363-364.

Park, E. Y., Koike, Y., Higashiyama, K., Fujikawa, S., Okabe, M. (1999). Effect of nitrogen source on mycelial morphology and arachidonic acid production in cultures of Mortierella alpina. J. Biosci. Bioeng., 88, $61-67$.

Peng, C., Huang, H., Ji, X., Liu, X., ..., You, J. (2010). A temperature-shift strategy for efficient arachidonic acid fermentation by Mortierella alpina in batch culture. Biochem. Eng. J., 53, 92-96.

Preez, J. C., Immelman, M., Kock, J. L. F., Kilian, S. G. (1997). The effect of acetic acid concentration on the growth and production of gamma-linolenic acid by Mucor circinelloides CBS 203.28 in fed-batch culture. World J. Microbiol. Biotechn. 13, 81-87. DOI: 10.1007/ BF02770812

Ratledge, C. (1992). Microbial lipids: commercial realities or academic curiosities. In D. J. Kyle, C. Ratledge (Eds.), Industrial Applications of Single Cell Oils (pp. 1-15). Champaign Il: American Oil Chemists' Society. 
Ratledge, C. (2004). Fatty acid biosynthesis in microorganisms being used for single cell oil production. Biochimie, $86,807-815$.

Šajbidor, J., Dobronova, S., Čertík, M. (1990). Arachidonic acid production by Mortierella sp. S-17 influence of C/N ratio. Biotechnol. Lett., 12, 455-456.

Shinmen, Y., Shimizu, S., Akimoto, K., Kawashima, H., Yamada, H. (1989). Production of arachidonic acid by Mortierella fungi. Appl. Microbiol. Biot., 31, 11-16.

Singh, A., Ward, O. (1997). Production of high yields of arachidonic acid in a fed-batch system by Mortierella alpina ATCC 32222. Appl. Microbiol. Biot., 48, 1-5.

Somashekar, D., Venkateshwaran, G., Sambaiah, K., Lokesh, B. (2003). Effect of culture conditions on lipid and gamma-linolenic acid production by Mucoraceous fungi. Process. Biochem., 38, 1719-1724.

Tanaka, Y., Aki, T., Hidaka, Y., Furuya, Y., ..., Kawamoto, S. (2002). Purification and characterization of a novel fungal alpha-glucosidase from Mortierella alliacea with high starch-hydrolytic activity. Biosci. Biotechn. Biochem., 66, 2415-2423.

Tribe, L., Briens, C., Margaritis, A. (1995). Determination of the volumetric mass transfer coefficient $(\mathrm{kLa})$ using the dynamic "gas out-gas in" method: Analysis of errors caused by dissolved oxygen probes. Biotechnol. Bioeng., 46, 388-392.

Willett, W. C., Stampfer, M. J., Manson, J., Colditz, G. A., ..., Speizer, F. E. (1993). Intake of trans fatty acids and risk of coronary heart disease among women. Lancet, 341, 581-585.

Zhang, J.-G., Wang, X.-D., Zhang, J.-N., Wei, D.-Z. (2008). Oxygen vectors used for S-adenosylmethionine production in recombinant Pichia pastoris with sorbitol as supplemental carbon source. J. Biosci. Bioeng., 105, 335-340. DOI: 10.1263/jbb.105.335

Zhu, M., Yu, L.-J., Wu, Y.-X. (2003). An inexpensive medium for production of arachidonic acid by Mortierella alpina. J. Ind. Microbiol. Biotechn., 30, 75-79.

Accepted for print - Zaakceptowano do druku: 2.03.2015

Received - Przyjęto: 16.01 .2015

For citation - Do cytowania

Cao, G., Guan, Z., Liu, F., Liao, X., Cai, Y. (2015). Arachidonic acid production by Mortierella alpina using raw crop materials. Acta Sci. Pol. Technol. Aliment., 14(2), 133-143. DOI: 10.17306/J.AFS.2015.2.15 